\title{
A screening and brief intervention for women in $\mathrm{OB} / \mathrm{GYN}$ care
}

\author{
Tatiana Balachova ${ }^{1 *}$, Mark Chaffin²* ${ }^{2 *}$ Barbara Bonner ${ }^{1}$, Galina Isurina ${ }^{3}$, Larissa Tsvetkova ${ }^{3}$, Elena Volkova ${ }^{4}$ \\ From INEBRIA 12th Congress, \\ Atlanda, GA, USA. 24-25 September 2015
}

\begin{abstract}
Background
Alcohol consumption levels in Russia are among the highest in the world [1]. Fetal Alcohol Spectrum Disorders in children are completely preventable by avoiding alcohol use during pregnancy [2]; yet, substantial numbers of women around the world consume alcohol during pregnancy mostly prior to pregnancy recognition [3-5]. A U.S. prevention model, Project CHOICES, utilized a pre-conceptional approach consisting of four counseling sessions and a family planning clinic visit [6]. A brief intervention protocol [7] and the CHOICES were adapted by the research team to design a brief intervention for implementation in public OB/GYN clinics in two regions in Russia. The objective of this study was to evaluate impact of the adapted protocol in reducing the risk for alcohol-exposed pregnancies (AEP) and alcohol consumption in general.
\end{abstract}

\section{Material and methods}

A dual-focused (alcohol use and the risk for an unplanned pregnancy) brief physician intervention (DFBPI) was designed to be delivered by OB/GYN physicians [8]. The intervention consisted of two face-toface, 5-minute sessions incorporated into routine clinic visits. A two-arm cluster-randomized controlled trial of the DFBPI was conducted at 20 district OB/GYN clinics. A total of 767 non-pregnant women, aged 18-44 years, at risk for an AEP (at-risk drinking, heterosexual intercourse, and the inconsistent use of contraception) were recruited for the study. Data included 90-day retrospective Time-Line Follow Back (TLFB) reports of daily alcohol consumption at baseline, 3, 6, and 12-months.

\footnotetext{
* Correspondence: Tatiana-Balachova@ouhsc.edu

'Pediatrics, The University of Oklahoma Health Sciences Center, Oklahoma City, USA

${ }^{2}$ School of Public Health, Georgia State University, Atlanta, USA

Full list of author information is available at the end of the article
}

Drinking trajectories were modeled using three-level semi-continuous piecewise latent trajectory models, with post-intervention intercepts and slopes conditional on treatment assignment. A subpopulation analysis was conducted for women who became pregnant during the 12 month interval for alcohol consumption prior to and after pregnancy recognition. Latent class transition models from baseline to post-intervention were tested to identify shifts in drinking patterns conditional on intervention condition.

\section{Results}

Physicians were able to implement, maintain skills, and deliver DFBPI. During the course of the study, 72 participants became pregnant. Participants in the DFBPI condition showed a larger decrease in alcohol consumption immediately following the intervention, which was maintained over the follow-up period. Newly pregnant women in the intervention condition showed a substantial drop in alcohol consumption in the weeks prior to pregnancy recognition, consistent with the targeted purpose of the intervention. Women in the intervention condition were more likely to transition out of a high alcohol use pattern and into a lower use pattern rather than into a binging pattern.

\section{Conclusions}

Results support the feasibility and efficacy of the DFBPI at OB/GYN clinics.

\footnotetext{
Acknowledgements

The study was supported by the National Institute on Alcohol Abuse and Alcoholism (NIAAA) Grant R01AA016234 and Fogarty International Center (Brain Disorders in the Developing World: Research Across the Lifespan). The authors wish to thank the study consultant Linda Sobell, PhD, of Nova Southeastern University for her invaluable contribution to the study; acknowledge contributions of the data base management team Nicholas Knowlton, MS, Sangeeta Agrawal, MS, and Som Bohora, MS; and thank graduate students from St. Petersburg State University, Nizhny Novgorod
} 
State Pedagogical University, and the University of Oklahoma Health

Sciences Center who assisted with the study.

Trial Registration

NCT01961050

\section{Authors' details}

'Pediatrics, The University of Oklahoma Health Sciences Center, Oklahoma City, USA. ${ }^{2}$ School of Public Health, Georgia State University, Atlanta, USA. ${ }^{3}$ St. Petersburg State University, St. Petersburg, Russia. ${ }^{4}$ Nizhny Novgorod State Pedagogical University, Nizhny Novgorod, Russia.

Published: 24 September 2015

\section{References}

1. World Health Organization: Global status report on alcohol and health. Geneva, Switzerland: World Health Organization; 2014.

2. Floyd RL, O'Connor MJ, Sokol RJ, Bertrand J, Cordero JF: Recognition and prevention of fetal alcohol syndrome. Obstet Gynecol 2005, 106:1059-64.

3. Nilsen P, Holmqvist M, Hultgren E, Bendtsen P, Cedergren M: Alcohol use before and during pregnancy and factors influencing change among Swedish women. Acta Obstet Gynecol Scand 2008, 87(7):768-774.

4. Balachova T, Bonner B, Chaffin M, Bard D, Isurina G, Tsvetkova L, Volkova E: Women's alcohol consumption and risk for alcohol-exposed pregnancies in Russia. Addiction 2012, 107(1):109-117.

5. Centers for Disease Control and Prevention: Alcohol Use and Binge Drinking Among Women of Childbearing Age - United States, 20062010. 2012, 534-8.

6. Floyd R L, Sobell M, Velasquez MM, Ingersoll K, Nettleman M, Sobell L, et al: Preventing alcohol-exposed pregnancies: A randomized controlled trial. American Journal of Preventive Medicine 2007, 32:1-10

7. Fleming MF, Lund MR, Wilton G, Landry M, Scheets D: The Healthy Moms study: the efficacy of brief alcohol intervention in postpartum women. Alcohol Clin Exp Res 2008, 32(9):1600-1606.

8. Balachova T, Bonner B, Chaffin M, Isurina G, Shapkaitz V, Tsvetkova L, Volkova E, Grandilevskaya I, Skitnevskaya L, Knowlton N: Brief FASD prevention intervention: physicians' skills demonstrated in a clinical trial in Russia. Addiction Science and Clinical Practice 2013, 8:1-10.

doi:10.1186/1940-0640-10-S2-O4

Cite this article as: Balachova et al:: A screening and brief intervention for women in OB/GYN care. Addiction Science \& Clinical Practice 2015 10(Suppl 2):O4

\section{Submit your next manuscript to BioMed Central} and take full advantage of:

- Convenient online submission

- Thorough peer review

- No space constraints or color figure charges

- Immediate publication on acceptance

- Inclusion in PubMed, CAS, Scopus and Google Scholar

- Research which is freely available for redistribution

Submit your manuscript at www.biomedcentral.com/submit
CioMed Central 